\title{
Clinical utility in the treatment of type 2 diabetes with the saxagliptin/metformin fixed combination
}

This article was published in the following Dove Press journal:

Patient Preference and Adherence

15 February 2014

Number of times this article has been viewed

\author{
George S Panagoulias' \\ John Doupis ${ }^{2,3}$ \\ 'Ist Department of Propaedeutic and \\ Internal Medicine, Athens University \\ Medical School, Laiko General \\ Hospital, Athens, Greece; ${ }^{2}$ Salamis \\ Naval Hospital, Athens, Greece; \\ ${ }^{3}$ Diabetes Division, latriko Paleou \\ Falirou Medical Center, Athens, \\ Greece
}

\begin{abstract}
Fixed-dose combination (FDC) products represent a widely accepted approach to type 2 diabetes treatment, given that monotherapies sometimes fail to meet the treatment targets obtaining a sustained reduction in micro- and macrovascular complications. Saxagliptin (SAXA)/ metformin (MET) FDC tablets can be used either alone or in combination with glyburide, thiazolidinediones, or insulin. It has been proven that the SAXA/MET combination leads to a significant improvement in glycemic control compared to placebo in patients with type 2 diabetes that is inadequately controlled with MET alone. In addition, this FDC has been proven to be safe for people with diabetes mellitus and established cardiovascular disease, elderly patients, and patients with impaired renal function $(>30 \mathrm{~mL} /$ minute), with dosage modification. Patient compliance, adherence, and persistence to the therapeutic regimen has been shown to be very good, while the titration of each compound according to the patient's profile is easy, given the availability of different formulations. The SAXA/MET FDC is a patient-friendly, dosage-flexible, and hypoglycemia-safe regimen with very few adverse events and a neutral or even favorable effect on body weight. It achieves significant glycosylated hemoglobin $\mathrm{A}_{1 \mathrm{c}}$ reduction helping the patient to achieve his/her individual glycemic goals.
\end{abstract}

Keywords: DPP-4 inhibitors, saxagliptin, metformin, fixed-dose combination products, FDC products

\section{Introduction to the challenges of treating type $\mathbf{2}$ diabetes}

Type 2 diabetes has become a pandemic, holding the leading position of causes of death in USA. ${ }^{1}$ The American Diabetes Association guidelines suggest that good glucose control is the cornerstone for the management of short- and long-term diabetes complications. ${ }^{2}$ Furthermore, major studies have shown that tight glycemic control plays a significant role in the prevention of both micro- and macrovascular complications. ${ }^{3-5}$

Although diabetes awareness has significantly increased worldwide, almost half of the diabetic patients remain undiagnosed, ${ }^{6}$ and a large number of patients on antidiabetic treatment remain inadequately controlled. ${ }^{7}$ Poor compliance to the treatment and drug-related side effects ${ }^{8,9}$ are the main reasons why long-lasting, good glycemic control is not achieved.

Initial diabetes management includes lifestyle changes, with a focus on healthy diet, weight control, and increased physical activity. Metformin (MET) is widely considered to be the best first step in oral antidiabetic treatment, not only because of its efficacy in reducing the glycosylated hemoglobin $\mathrm{A}_{1 \mathrm{c}}\left(\mathrm{HbA}_{1 \mathrm{c}}\right)$, but also due to its low 
risk for hypoglycemia, its positive or neutral effect on body weight, its rare incidence of adverse effects, and its low cost. $^{10}$

Early addition of a second oral hypoglycemic agent (OHA) or insulin has been suggested for cases in which MET monotherapy along with lifestyle modifications fail to achieve optimal $\mathrm{HbA}_{1 \mathrm{c}}$ levels within 3-6 months., ${ }^{2,10,11}$ Adherence to medication in general depends on multiple factors, categorized by Blackburn et al into five groups: 1) characteristics of the patient; 2) characteristics of the treatment regimen; 3) features of the disease; 4) prescriber-level factors (including patient-physician relationship); and 5) the clinical setting. ${ }^{12}$ It has been proven that nonadherence to medication is very frequent in people with diabetes mellitus (DM) ${ }^{13}$ and leads to increased morbidity and mortality. ${ }^{14}$ Given that good patient compliance to hypoglycemic therapy is of crucial importance, tight glucose control must be achieved; the combination of two OHAs into a single tablet has been proven preferable to the administration of two separate agents, as this significantly simplifies the therapeutic regimen. ${ }^{15}$

The existing OHA single-tablet combinations include MET and sulfonylurea, MET and meglitinides, MET and thiazolidinediones (TZDs), sulfonylureas and TZD, and, more recently, MET and DPP-4 inhibitors (Table 1). ${ }^{16}$ DPP-4 inhibitors combined with MET have shown better outcomes in patients with poor glycemic control, compared to individual monotherapy. ${ }^{17,18}$

\section{Review of current and emerging therapies}

It has been more than 80 years since British clinician Harry Himsworth's observations ${ }^{19}$ led to the conclusion that diabetes may not be the result only of the absolute lack of insulin, leading to the definition of type 2 diabetes. Only in 1958, though, did the first sulfonylurea became available on the market for the treatment of type 2 diabetes. ${ }^{19}$

Sulfonylureas are insulin secretagogues. They enhance insulin secretion by stimulating the pancreatic $\beta$-cells, consequently reducing the blood glucose through increased activity of the intracellular insulin receptors. ${ }^{20}$ Their main adverse events are hypoglycemia, mild weight gain, and possible early exhaustion of the $\beta$-cell. ${ }^{10}$

MET is considered to be the cornerstone of type 2 diabetes treatment. It has been used since 1959 in Europe, but only after 1995 in USA, due to the US Food and Drug Administration (FDA)'s concerns about possible toxicity. ${ }^{21}$ Its mechanisms of action include reduction of the hepatic glucose output and increase of insulin sensitivity. The most common adverse events of MET are gastrointestinal, sometimes leading to discontinuation of the treatment. ${ }^{5,22}$

Meglitinides are also insulin secretagogues, acting by inhibiting the adenosine triphosphate (ATP)-dependent potassium channels of the $\beta$-cells. They present a short half-time of action, thus have to be administered before each meal. Repaglinide and nateglinide are the two representatives of this category. Meglitinides are potent in reducing $\mathrm{HbA}_{1 \mathrm{c}}$, and present lower risk for hypoglycemia compared to sulfonylureas. ${ }^{22}$

Another class of OHAs are $\alpha$-glucosidase inhibitors (acarbose and miglitol). These act by reducing the digestion rate of polysaccharides in the jejunum, presenting no effect on simple monosaccharides, ${ }^{22}$ and lower $\mathrm{HbA}_{1 \mathrm{c}}$ up to $0.8 \%$. Gastrointestinal side effects are the main reason for discontinuation of $\alpha$-glucosidase inhibitor treatment. ${ }^{23}$

TZDs are peroxisome proliferator-activated receptor- $\gamma$ activators. The only two chemical formulations in use, with various regional restrictions imposed worldwide, are pioglitazone and rosiglitazone. Their main mechanism of action in reducing hyperglycemia is through upregulation of insulin absorption from skeletal muscles and adipose tissue and reduction of gluconeogenesis. ${ }^{24}$ Apart from the fact that common side effects are weight gain and increased risk for bone fractures and peripheral edema, their main problem is that they are related to increased risk for myocardial infarction, while the latter is related to increased risk for macular edema and increased low-density lipoprotein levels. ${ }^{25-27}$

The only amylin mimetic, pramlintide, an injectable synthetic analog of the $\beta$-cell hormone amylin that acts by delaying gastric emptying, is currently approved for use only in USA. ${ }^{10,28-30}$ Gastrointestinal side effects, the risk of severe hypoglycemic events, and the need to be coadministered with insulin, ${ }^{31}$ along with the lack of sufficient data concerning long-term safety, may be the reason for pramlintides limited use in USA and for its not being licensed in Europe. ${ }^{10}$

Sodium-glucose cotransporter 2 inhibitors are a novel class of OHA for the treatment of type 2 diabetes. They act by inhibiting the sodium-glucose transport protein subtype 2 , which inhibits renal glucose reabsorption, consequently resulting in increased urinary glucose excretion. Currently, dapagliflozin is licensed only in Europe, while canagliflozin is licensed only in USA. ${ }^{32}$

Insulin has been the only hypoglycemic agent able to achieve euglycemia both in fasting and postprandial states, followed by a consequent $\mathrm{HbA}_{1 \mathrm{c}}$ reduction to optimal levels. The main problems from insulin treatments are weight gain, ${ }^{33}$ risk of hypoglycemia, ${ }^{33}$ and the need for extensive training of 
Table I Completed clinical trials for saxagliptin supervised by the US National Institutes of Health

\begin{tabular}{|c|c|c|c|c|c|c|}
\hline Trial $^{\mathbf{a}}$ & $\begin{array}{l}\text { Type of } \\
\text { study }\end{array}$ & $\begin{array}{l}\text { Number of } \\
\text { participants }\end{array}$ & $\begin{array}{l}\text { Duration } \\
\text { (weeks) }\end{array}$ & Compared ${ }^{b}$ & $\mathrm{HbA}_{1 \mathrm{c}}{ }^{\mathrm{c}}$ & FPG $^{d}$ \\
\hline NCTOI068743 & $\mathrm{BE}$ & 24 & 24 & $\begin{array}{l}\text { SAXA } 2.5 \mathrm{mg} / \text { MET } 850 \mathrm{mg} \text { FDC vs } \\
\text { SAXA } 2.5 \mathrm{mg}+\text { MET } 850 \mathrm{mg}\end{array}$ & & \\
\hline NCTOII92I52 & BE & 30 & 24 & $\begin{array}{l}\text { SAXA } 5 \mathrm{mg} / \text { MET I,000 mg XR FDC } \\
\text { vs SAXA } 5 \mathrm{mg}+\text { MET } 2 \times 500 \mathrm{mg} \text { XR }\end{array}$ & & \\
\hline NCT0I0687I7 & BE & 27 & 24 & $\begin{array}{l}\text { SAXA } 2.5 \mathrm{mg} / \text { MET } 500 \mathrm{mg} \text { FDC vs } \\
\text { SAXA } 2.5 \mathrm{mg}+\text { MET } 500 \mathrm{mg}\end{array}$ & & \\
\hline NCT00899470 & $\mathrm{BE}$ & 24 & 24 & $\begin{array}{l}\text { SAXA } 2.5 \mathrm{mg} / \text { MET } 500 \mathrm{mg} \text { IR vs } \\
\text { SAXA } 5 \mathrm{mg}+\text { MET } 500 \mathrm{mg} \text { IR }\end{array}$ & & \\
\hline NCT003270I5 & $\mathrm{EF} / \mathrm{SA}$ & 1,306 & 24 & $\begin{array}{l}\text { SAXA } 5 \mathrm{mg}+\text { MET } 500-2,000 \mathrm{mg} \text { vs } \\
\text { SAXA } 10 \mathrm{mg}+\text { MET } 500-2,000 \mathrm{mg} \text { vs } \\
\text { SAXA } 5 \mathrm{mg} \text { vs MET } 500-2,000 \mathrm{mg}\end{array}$ & $-2.53 \pm 0.070$ & $-59.8 \pm 2.34$ \\
\hline NCT00I 21641 & $\mathrm{EF} / \mathrm{SA}$ & 401 & 24 & $\begin{array}{l}\text { SAXA } 2.5 \mathrm{mg}, 5 \mathrm{mg} \text {, or } 10 \mathrm{mg} \text { - placebo + } \\
\text { MET } 500-2,000 \mathrm{mg}\end{array}$ & $-0.46 \pm 0.10$ & $-8.67 \pm 3.74$ \\
\hline NCT00950599 & $\mathrm{EF}$ & 423 & 24 & SAXA (2.5-5-10-20-40-100 mg) vs PL & Multiple results & Multiple results \\
\hline NCTOII92I39 & BE & 30 & 24 & $\begin{array}{l}\text { SAXA } 5 \mathrm{mg} / \mathrm{MET} 500 \mathrm{mg} \text { XR FDC } \\
\text { vs SAXA } 5 \mathrm{mg}+\text { MET } 500 \mathrm{mg} \text { XR }\end{array}$ & & \\
\hline NCT00295633 & $\mathrm{EF} / \mathrm{SA}$ & 565 & 24 & $\begin{array}{l}\text { SAXA } 2.5 \mathrm{mg}+\text { TZDS vs SAXA } 5 \mathrm{mg}+ \\
\text { TZDS vs PL + TZDS }\end{array}$ & $-0.94 \pm 0.075$ & $-17.3 \pm 2.94$ \\
\hline NCT003I6082 & $\mathrm{EF} / \mathrm{SA}$ & 365 & 24 & SAXA $2.5-5 \mathrm{mg}$ vs PL & $-0.66 \pm 0.102$ & $-12.5 \pm 4.48$ \\
\hline NCT00I 21667 & $\mathrm{EF} / \mathrm{SA}$ & 743 & 24 & $\begin{array}{l}\text { SAXA 2.5-5-10 mg + MET } \\
\text { (flexible dose) + pioglitazone } \\
\text { I5-45 mg (as needed for rescue) vs } \\
\text { PL/MET (flexible dose) + pioglitazone } \\
\text { I5-45 mg (as needed for rescue) }\end{array}$ & $-0.69 \pm 0.07$ & $-22.03 \pm 2.49$ \\
\hline NCT009I8I38 & $\mathrm{EF} / \mathrm{SA}$ & 93 & 24 & $\begin{array}{l}\text { SAXA } 5 \mathrm{mg} / \mathrm{MET} \text { I,500 mg FDC vs } \\
\text { MET } 2,000 \mathrm{mg}\end{array}$ & & $-19.0 \pm 5.69^{*}$ \\
\hline NCT00313313 & $\mathrm{EF} / \mathrm{SA}$ & 768 & 24 & $\begin{array}{l}\text { SAXA } 2.5-5 \mathrm{mg}+7.5 \mathrm{mg} \text { glyburide } \\
\text { vs PL }+7.5 \mathrm{mg} \text { glyburide }\end{array}$ & $\begin{array}{l}-0.64 \pm 0.059 \\
-9.7 \pm 2.39\end{array}$ & $-9.7 \pm 2.39$ \\
\hline NCTOII 28153 & $\mathrm{EF} / \mathrm{SA}$ & 257 & 24 & SAXA $5 \mathrm{mg}$ vs PL & -0.89 to -0.60 & -12.67 to 2.11 \\
\hline NCT00757588 & $\mathrm{EF} / \mathrm{SA}$ & 455 & 24 & $\begin{array}{l}\text { SAXA } 5 \mathrm{mg}+\mathrm{INS} \pm \text { MET vs PL }+ \\
\text { INS } \pm \text { MET }\end{array}$ & $-0.73 \pm 0.054$ & $-10.1 \pm 2.87$ \\
\hline NCT00575588 & & 858 & 104 & $\begin{array}{l}\text { SAXA } 5 \mathrm{mg}+\text { MET vs } \\
5-20 \mathrm{mg} \text { glipizide + MET }\end{array}$ & $\begin{array}{l}-0.74 \pm 0.038 \\
-0.4 I \pm 0.04 I\end{array}$ & \\
\hline NCTOI006590 & $\mathrm{EF} / \mathrm{TO}$ & 286 & & $\begin{array}{l}\text { SAXA } 5 \mathrm{mg}+\text { MET I,500 mg vs } \\
\text { MET I,500-2,500 mg }\end{array}$ & $-0.47 \pm 0.06$ & $\begin{array}{l}-1.07 \pm 0.16 \\
(\mathrm{mmlols} / \mathrm{L})\end{array}$ \\
\hline NCT00698932 & $\mathrm{EF} / \mathrm{SA}$ & 568 & 24 & SAXA $5 \mathrm{mg}$ vs PL & $-0.84 \pm 0.067$ & $-16.13 \pm 2.586$ \\
\hline NCT00918879 & $\mathrm{EF} / \mathrm{SA}$ & 213 & 24 & SAXA $5 \mathrm{mg}$ vs PL & $-0.5 I \pm 0.098$ & $-10.35 \pm 3.827$ \\
\hline NCT00683657 & $\mathrm{EF} / \mathrm{SA}$ & 93 & 24 & SAXA $5 \mathrm{mg}+$ MET XR vs PL + MET XR & & $-13.8 \pm 2.99 *$ \\
\hline NCT0066I362 & $\mathrm{EF} / \mathrm{SA}$ & 570 & 24 & SAXA 5 mg + MET vs PL + MET & $-0.78 \pm 0.05$ । & $-20.52 \pm 2.051$ \\
\hline NCT006।4939 & $\mathrm{EF} / \mathrm{SA}$ & 170 & 52 & SAXA 2.5 mg vs PL (renal impairment) & $-1.35 \pm 0.174$ & $\begin{array}{l}-14.96 \pm 12.873 \\
-40.32 \pm 20.789 \\
-40.28 \pm 45.470\end{array}$ \\
\hline
\end{tabular}

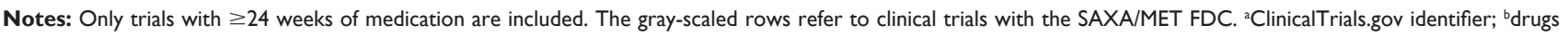
compared; cadjusted mean change from baseline. Referring to maximum dose of the drug licensed for human use (\%); 'adjusted change from baseline. Referring to maximum dose of the drug licensed for human use $(\mathrm{mg} / \mathrm{dL})$; *change from baseline in 24-hour mean weighted glucose at week $4(\mathrm{mg} / \mathrm{dL})$.

Abbreviations: $B E$, bioequivalence; EF, efficacy; FDC, fixed-dose combination; FPG, fasting plasma glucose; HbA $\mathrm{Ac}_{\mathrm{Ic}}$, glycosylated hemoglobin $\mathrm{A}_{\mathrm{Ic}}$; IR, immediate release; MET, metformin; PL, placebo; SA, safety; SAXA, saxagliptin; TO, tolerability; TZDs, thiazolidinediones; XR, extended release; vs, versus; NCT, clinical trials identifier.

the patient in regards to the use of equipment. ${ }^{34} \mathrm{New}$ insulin analogs, such as degludec ${ }^{35}$ and LY2605541 molecule, ${ }^{36}$ are under development.

Recently, bariatric surgery has entered the DM treatment field, arguing that it is a surgical disease. ${ }^{37}$ Meta-analyses have failed, however, to conclude whether remission of DM after metabolic surgery is sustained. ${ }^{38}$ The pharmaceutical industry is also targeting the development of new antidiabetic agents, such as insulin receptor signaling activators ${ }^{39}$ and insulin receptor tyrosine kinase activators, ${ }^{40}$ which are currently under investigation, with promising results so far. 
Finally, glucagon-like peptide-1 (GLP-1) receptor agonists and dipeptidyl peptidase-4 (DPP-4) inhibitors are two well-established new classes of antidiabetic agent based on the incretin effect.

\section{The incretin effect}

Clinical studies in the 1960s proved that oral glucose ingestion induces a greater increase in plasma insulin levels compared to intravenous administration of the same glucose amount. This was defined as the incretin effect, which is part of the intestinal hormone release, after oral glucose ingestion, resulting in increased insulin secretion. ${ }^{41,42}$

The physiology of incretin effect is based mainly on the secretion of glucose-dependent insulinotropic polypeptide (GIP) from the intestinal K-cells and GLP-1 from the L-cells of the lower gut, after food intake. Both engage to structurally distinct G-protein-coupled receptors in $\beta$-cells but GIP only to $\alpha$-cells and GKP- 1 only to $\beta$-cells of the pancreas. This leads to a rapid increase of the c-cyclic adenosine monophosphate and the intracellular calcium levels, followed by a consequent increase in insulin production. ${ }^{43,44}$

GIP and GLP-1 are extensively and rapidly degraded by the enzyme DPP-4, which cleaves two terminal amino acids, converting the active polypeptides to their inactive form. Both the active and inactive forms of GIP and GLP-1 are cleared by the kidneys. Because of the rapid secretion and rapid inactivation of both GIP and GLP-1, their biologic actions are very short-lived and rapidly reversible. ${ }^{45}$

GIP induces lipogenesis and stimulates glucagon secretion, while GLP-1 suppresses glucagon secretion during the postprandial period, slows gastric emptying, and increases satiety. ${ }^{44}$ GIP does not potentiate the antidiabetic effects of GLP-1 in patients with type 2 diabetes. ${ }^{46}$

The antidiabetic effect of GLP-1 has opened new horizons for pharmaceuticals toward the development of new agents for treatment of type 2 diabetes based on the incretin effect. As a result, GLP-1 receptor agonists were produced in order to mimic and enhance the GLP-1 action; DPP-4 inhibitors were also produced in order to inhibit the action of GLP-1 inhibitors (DPP-4) and subsequently increase the levels of endogenously produced GLP-1.

\section{GLP-I receptor agonists}

Currently, exenatide, liraglutide, and lixisenatide are commercially available. Albiglutide, a novel GLP-1 analog, is filed for approval in both USA and Europe, while dulaglutide is still in a Phase III study. ${ }^{47-49}$ GLP-1 analogs are a new, hypoglycemia-safe class of injectable antidiabetic agent, presenting significant glucose-lowering potency in patients with type 2 diabetes. When used as an adjunct to other treatments, they appear to lower $\mathrm{A}_{1 \mathrm{c}}$ levels by $0.5 \%$ to $1 \%{ }^{50}$ Although some patients may experience gastrointestinal side effects (especially nausea), mainly at the beginning of therapy, patient treatment satisfaction is high, mainly due to convenience, flexibility, weight loss, lack of hypoglycemia, and glucose-lowering efficacy of the medication. ${ }^{51,52}$

\section{DPP-4 inhibitors}

Also known as gliptins, DPP-4 inhibitors are another novel class of OHA, based on the incretin effect concept. The currently available gliptins worldwide are sitagliptin, vildagliptin, saxagliptin (SAXA), linagliptin, and alogliptin, while gemigliptin is available only in South Korea. ${ }^{50}$ Dutogliptin has completed Phase III clinical trials. ${ }^{53}$ According to the consensus statement of the American Diabetes Association and the European Association for the Study of Diabetes (EASD), DPP-4 inhibitors may be used as a second-line treatment for type 2 diabetes, after MET. ${ }^{10}$ The hypoglycemic action of DPP-4 inhibitors is mainly based on the increase of insulin secretion in a glucose-dependent way, as well as the suppression of glucagon secretion, as a result of the DPP-4 enzyme inhibition and the consequent increase of the circulating GLP-1. This results in an $\mathrm{HbA}_{1 \mathrm{c}}$ reduction of up to $0.8 \% .{ }^{54}$ Their main side effects include gastrointestinal discomfort as well as urticaria and angioedema $;{ }^{10}$ however, their low risk for hypoglycemia and good tolerance, together with their complementary mechanism of action in combination with MET, rank them high in the choice of therapeutic regimen..$^{55}$

\section{SAXA}

SAXA was the third DPP-4 inhibitor to be approved for human use by the FDA on July 31, 2009. ${ }^{56}$ Its chemical name, according to the International Union of Pure and Applied Chemistry (IUPAC) is (1S,3S,5S)-2-((2S)-2-Amino2-(3-hydroxyadamantan-1-yl)acetyl)-2-azabicyclo[3.1.0] hexane-3-carbonitrile hydrate, and its molecular formula and weight are $\mathrm{C} 18 \mathrm{H} 25 \mathrm{~N} 3 \mathrm{O} 2 \cdot \mathrm{H} 2 \mathrm{O}$ and 333.43 (315.41 anhydrous), respectively.

SAXA appears as a water-soluble, white to off-white, crystalline powder, and its $\mathrm{pKa}$ value is 7.3. Its commercial name is Onglyza (Bristol-Myers Squibb, New York, NY, USA; AstraZeneca, London, UK) and it is on the market as an immediaterelease, film-coated tablet containing $5 \mathrm{mg}$ SAXA, supplied in alu/alu blister packaging. ${ }^{57}$ SAXA is FDA-approved to be usedalong with diet and exercise - alone or in combination with other OHAs (MET, sulfonylureas [glyburide], and TZDs). ${ }^{58}$ It is also licensed for triple oral therapy and in combination with 
insulin therapy with or without MET. ${ }^{59}$ The efficacy and safety, as well as the bioequivalence studies used for granting the license in the US, are summarized in Table 2.

SAXA, when administered orally alone at the maximum dose of $5 \mathrm{mg}$, achieves a mean $\mathrm{HbA}_{1 \mathrm{c}}$ reduction of $0.8 \%$ and a mean fasting plasma glucose reduction of $22 \mathrm{mg} / \mathrm{dL}$. When coadministered with each therapeutic category of OHAs, it additionally reduces the mean $\mathrm{HbA}_{1 \mathrm{c}}$ by $0.6 \%-0.7 \%$. Furthermore, when it is coadministered with MET, at maximum tolerated dose and in MET-naïve patients, it achieves a mean $\mathrm{HbA}_{1 \mathrm{c}}$ reduction of $2.5 \%$, compared to placebo/MET combination.

The efficacy, safety, and the bioequivalence of SAXA/MET fixed-dose combination (FDC), in various dosage combinations, has been proven to be equal to administration of each compound separately, as shown in Table $1 .{ }^{60}$ Finally, according to the results of the SAVOR-TIMI 53 study of saxagliptin versus placebo, when added to standard of care in patients with T2DM at high CV risk, no increased risk of cardiovascular death, myocardial infarction, or ischemic stroke was demonstrated.

\section{Materials and methods}

A systematic search strategy was performed to identify randomized controlled trials in both MEDLINE (US National Library of Medicine, Bethesda, MD, USA) and ClinicalTrials.gov (US National Library of Medicine) until July 2013. The terms "saxagliptin," "saxagliptin/metformin fixed dose combination," "saxagliptin/metformin FDC," "combination saxagliptin/metformin," and "fixed dose of saxagliptin/metformin," were incorporated into an electronic

Table 2 Existent dipeptidyl peptidase-4/metformin combinations worldwide (oral tablets)

\begin{tabular}{ll}
\hline Combination & Dose (mg) \\
\hline Sitagliptin/metformin hydrochloride & $50 / 500$ \\
& $50 / 850$ \\
Sitagliptin/metformin hydrochloride extended release & $50 / 1,000$ \\
& $50 / 500$ \\
Vildagliptin/metformin hydrochloride & $50 / 1,000$ \\
& $100 / 1,000$ \\
& $50 / 500$ \\
Saxagliptin/metformin hydrochloride extended release & $50 / 850$ \\
& $50 / 1,000$ \\
& $5 / 500$ \\
Linagliptin/metformin hydrochloride & $5 / 1,000$ \\
& $2.5 / 1,000$ \\
& $2.5 / 500$ \\
Alogliptin/metformin hydrochloride & $2.5 / 850$ \\
& $2.5 / 1,000$ \\
& $12.5 / 500$ \\
& $12.5 / 1,000$ \\
\hline
\end{tabular}

Note: Data from www.drugs.com. ${ }^{95}$

Patient Preference and Adherence 20I4:8 search strategy. ${ }^{61}$ Only papers in the English language were included in the search.

Studies with a duration of $\geq 24$ weeks were included (Table 1). Trials with the SAXA/MET FDC are gray-scaled.

\section{Methods of improving adherence to therapy: focus on combination formulations including SAXA/MET acceptability, adherence, and uptake}

Nowadays, many new hypoglycemic agents are available for the treatment of type 2 diabetes, many of which are licensed, even for triple therapy. Thus, the quest for optimal glucose control often involves complex treatments, including multiple oral medications combined, sometimes with one or more insulin injections a day. This often affects adherence to the diabetes therapy, ultimately leading to inadequate glucose control.

Patient compliance, adherence, and persistence to the therapeutic regimen have been proven, since the Hippocratic era, to be crucial for the management of chronic diseases (Table 1).

A systematic review regarding patients' adherence to DM medication has shown that patients on either OHAs and insulin presented poor compliance to the treatment. ${ }^{13}$ Additionally, nonadherence to medication has been reported to be associated with higher hospitalization and mortality rates in patients with type 2 diabetes. Patients with poor adherence were younger, with less comorbidities as expected, presenting higher levels of $\mathrm{HbA}_{1 \mathrm{c}}$ during follow-up. ${ }^{62}$

In accordance with the above, the World Health Organization has reported that nonadherence to treatment is the leading cause of increased morbidity, mortality, and health care cost in preventable diseases. ${ }^{63}$ This assertion led to the formation of fixed-combined medication, called FDC products, in order to reduce the number of pills required per day and achieve the pursued targets, increasing adherence to the treatment. It has been shown that patients on monotherapy with inadequate glucose control are significantly improved when switching to FDCs compared to the add-on of a second OHA in a combination therapy. Additionally, conversion from monotherapy or polytherapy to an FDC has been proven to improve patient adherence rates by $23 \%$ and $16 \%$, respectively. ${ }^{64}$

A combined medication should ideally present complementary mechanisms of action and compatible pharmacokinetic characteristics. The combination of agents into a single tablet has been considered as an even better therapeutic option because it simplifies considerably the therapeutic regimen and maximizes patient compliance. ${ }^{15}$

Given the above, the new SAXA/MET FDC represents a good choice for amplifying patients' compliance and 
adherence to the therapeutic regimen. Given that the FDC is on the market in various milligram combinations (Table 1), the titration of each compound is easy and feasible, offering the clinician the flexibility to titrate up to the maximum tolerated dose for MET along with SAXA in a combined pill.

Even though coadministration of SAXA with submaximal doses of MET has not shown significant difference in $\mathrm{HbA}_{1 \mathrm{c}}$ reduction compared to a maximal dose of MET alone, ${ }^{65}$ SAXA add-on to low MET dosages seems to be a good alternative treatment choice for patients with intolerance to high doses of MET.

\section{Efficacy, safety, and tolerability of SAXA/MET FDC}

Three recent studies have shown that SAXA/MET FDC was bioequivalent to separate SAXA and MET coadministration in both fasting and postprandial states, for both immediate and extended-release formulations. Moreover, tolerability, safety, and efficacy of the fixed formulations of SAXA/MET were comparable to those of each individual component when coadministered. ${ }^{66,67}$ Food consumption was found not to affect the pharmacokinetics of SAXA and MET when administered together as one formulation. ${ }^{67}$

A recent study has shown that adding SAXA to MET led to a statistically significant improvement in glycemic control compared to placebo in patients with type 2 diabetes inadequately controlled with MET alone. ${ }^{68}$ Since pharmacokinetics do not differ when SAXA and MET are given as a fixed combination, it is reasonable to expect the same results in the glycemic parameters. ${ }^{66}$

Additionally, it has been proven that DPP-4 inhibitors, and especially SAXA, when coadministered with MET, provide an additive or even synergistic effect on metabolic control in patients with type 2 diabetes. ${ }^{69}$ One study, comparing SAXA/ glyburide combination with up-titrated glyburide, showed significantly better glucose control in the SAXA/glyburide group, as determined by $\mathrm{HbA}_{1 \mathrm{c}}$ changes from baseline. This effect was sustained throughout the study. ${ }^{70}$ It has also been shown that, although sulfonylureas may be more effective in $\mathrm{HbA}_{1 \mathrm{c}}$ reduction in maximal doses compared to gliptins, their potential adverse events are maximized. ${ }^{71}$

A crucial point in diabetes treatment with gliptins is cardiovascular safety. ${ }^{7}$ In a pooled analysis of Phase III clinical trials, SAXA has shown that is well tolerated in patients with established cardiovascular disease, as well as in patients with more than two risk factors for cardiovascular disease. ${ }^{72}$ Concerns regarding cardiovascular safety have been raised since $2008 .{ }^{73}$ SAXA is now being evaluated in the SAVOR-TIMI-53 [34] for cardiovascular safety as well as for its possible role in reducing the risk of cardiovascular events. ${ }^{74}$ Preliminary data have shown that SAXA have met the primary safety objective of noninferiority; but did not meet the primary efficacy objective of superiority for a composite end point of cardiovascular death, nonfatal myocardial infarction, or nonfatal ischemic stroke, when added to the patient's current standard of care (with or without other antidiabetic therapies), compared to placebo. ${ }^{75}$ With regard to this, the SAXA/MET combination may be an alternative to the classical MET/sulfonylurea combination. ${ }^{74}$

SAXA/MET FDC has also been evaluated in older patients with type 2 diabetes, especially for safety and tolerance. The results of a post hoc analysis of pooled data from patients $>65$ years old from five Phase III clinical trials of 24-week duration have shown that SAXA/MET FDC was significantly effective in diabetes management and also very well tolerated. The risk of hypoglycemic events was low and adverse events were, in general, similar to those of younger patients. ${ }^{76}$

It is common knowledge that MET should be used with caution in patients with impaired renal function, as determined by estimated glomerular filtration rate (e-GFR), using any of the available formulas. ${ }^{77}$ In case e-GFR is less than $30 \mathrm{~mL} /$ minute, MET should be discontinued. Special attention should be given to patients with fluctuations in renal status. ${ }^{78}$ SAXA, on the other hand, requires no dose adjustment for patients with mild renal impairment (up to $50 \mathrm{~mL} /$ minute), whereas dose reduction by half is necessary for patients with e-GFR between 30-50 mL/minute. SAXA should be discontinued if e-GFR is less than $30 \mathrm{~mL} /$ minute; ${ }^{79}$ however, the lowest dose of SAXA (2.5 mg), administrated once daily, showed sustained efficacy and good tolerability for patients with type 2 diabetes and end-stage renal disease. ${ }^{80}$

In line with the above, SAXA/MET FDC 2.5/500 mg can be safely prescribed to subjects with type 2 diabetes and renal impairment with a e-GFR as low as $30 \mathrm{~mL} /$ minute.

\section{Patient-focused perspectives, such as quality of life, patient satisfaction/ acceptability, and adherence}

When individualizing diabetes treatment, the goals and the personal preferences of the patient should be matched to the clinical profile of the hypoglycemic agents. ${ }^{81}$ Moreover, psychosocial barriers, fear of hypoglycemia, susceptibility to side effects, and drug-induced weight gain potential, should be taken into account for a tailor-made approach to the antidiabetic treatment. ${ }^{8,82}$ 
It has been proven that fear of adverse events has a great impact on patient adherence to medication, ${ }^{82}$ thus a hypoglycemia-safe class of OHAs with very few adverse events could possibly improve compliance. The SAXA/MET FDC represents a hypoglycemia-safe choice with excellent tolerability and very few adverse events that also provides a significant contribution to $\mathrm{HbA}_{1 \mathrm{c}}$ reduction in patients with type 2 diabetes. ${ }^{68,83}$ Adverse events of SAXA/MET FDC in both older ( $>65$ years) and younger subjects have been proven to be very low in a post hoc analysis. ${ }^{76}$

Another significant determinant of treatment compliance has been proven to be the age of the patient. Studies have shown that younger patients tend to present poor glycemic control and a large number of prescribed OHAs. ${ }^{8}$ In addition, younger patients with DM present lower adherence to therapy compared to older ones. ${ }^{6}$ These differences between younger and older patients could possibly be attributed to unscheduled meals due to the way of living and working, and discrepancies in intra-daily nutrient intake. The frequency and timing of the dosing of the antidiabetic agents seems to be very important in these cases ${ }^{84} \mathrm{FDCs}$ provide flexible regimens with reduced number of pills and easy titration of the medications. SAXA/MET fixed combination may represent an ideal choice for the management of diabetes in this age group. ${ }^{76,85}$

The fear of weight gain is another factor that could significantly influence adherence to diabetes treatment as well. ${ }^{84}$ The effect of DPP-4 inhibitors on body weight has been proven to be neutral or mildly favorable. It has also been shown that their mild weight-lowering effect is maximized when they are coadministered with MET ${ }^{86}$ Given that weight control is very important for patients with type 2 diabetes, preference should be given to hypoglycemia-safe and weightneutral agents, targeting also maximum compliance to the treatment. ${ }^{86}$ The SAXA/MET fixed combination seems to address this crucial point of adherence. In younger ages, weight control is even more significant, since obesity bears a negative psychosocial burden as well. ${ }^{87}$

It is noteworthy that the main disadvantage of DPP-4 inhibitors is their high cost. It has been proven that better adherence to treatment of chronic diseases is associated with significant cost reduction for the health care system, mainly due to the reduction in long-term complications of the diseases. ${ }^{63,88,89}$ Unfortunately, there is a lack of data regarding the possible association between the use of DPP-4 inhibitors for type 2 diabetes and the direct health care cost. To estimate the possible cost effectiveness of DPP-4 inhibitors, models based on cost and quality-adjusted life years (QALYs) estimation have been used. In such models, the use of the SAXA/MET combination has been proven to be cost-effective, from the perspective of the social security system in Argentina.${ }^{90} \mathrm{~A}$ simulation model based on the United Kingdom Prospective Diabetes Study (UKPDS) Outcomes Model (68) has been used to calculate the disease progression and to estimate the economic and health treatment consequences, derived from micro- and macrovascular complications in people with type 2 diabetes, during a 20-year follow up. ${ }^{90}$ In this model, a SAXA/MET-treated group was compared to a SU/MET-treated group. The former presented a lower number of both fatal and nonfatal macrovascular events compared to the latter. Although the total cost to treat, of the SAXA/MET-treated group was $15 \%$ higher than that of the SU/MET group, the treatment with SAXA/MET resulted in a higher number of QALYs and life-years gained, while the incremental cost per QALY and life-year gained was US\$7,374 and US\$20,490, respectively. ${ }^{90}$

In another discrete event-simulation model, the add-on of SAXA to MET was compared to the add-on of pioglitazone or rosiglitazone to MET, in a 3-year follow-up. The estimated cost-utility ratio (cost per QALY) and budget impact model was built to simulate the economic impact of SAXA. From the perspective of private paying source, ie, the payment of the medication directly by the patient, the projection showed that the SAXA/MET combination presented lower costs compared to the TZD/MET combination in patients with type 2 diabetes who had not reached the $\mathrm{HbA}_{1 \mathrm{c}}$ goal with MET monotherapy. ${ }^{91}$

\section{Conclusion}

Achieving good outcomes in diabetes has been proven to be associated with the treatment selection as well as with the adherence of the patient to the therapy. Thus, full individualization of the diabetes treatment should be focused on meeting the needs of the patient - fitting in with his/ her everyday life schedule and addressing his/her personal psychosocial aspects. ${ }^{92,93}$ From the patient's point of view, it remains unclear whether better quality of life is achieved just by alleviation of the symptoms of the disease. ${ }^{94}$

It seems that the SAXA/MET FDC is a patientfriendly, dosage-flexible, and hypoglycemia-safe regimen. Combining very few adverse events with a neutral or even favorable effect on body weight, it is also potent enough to achieve significant $\mathrm{HbA}_{1 \mathrm{c}}$ reduction and help the patient to achieve his/her individual glycemic goals.

\section{Disclosure}

The authors report no conflicts of interest in this work. 


\section{References}

1. 2011 National Diabetes Fact Sheet [webpage on the Internet]. Atlanta, GA: Centers for Disease Control and Prevention; 2013. Available from: http://www.cdc.gov/diabetes/pubs/factsheet11.htm. Accessed August 27, 2013.

2. American Diabetes Association. Standards of medical care in diabetes - 2013. Diabetes Care. 2013;36 Suppl 1:S11-S66.

3. [No authors listed]. Intensive blood-glucose control with sulphonylureas or insulin compared with conventional treatment and risk of complications in patients with type 2 diabetes (UKPDS 33). UK Prospective Diabetes Study (UKPDS) Group. Lancet. 1998;352(9131):837-853.

4. [No authors listed]. The effect of intensive treatment of diabetes on the development and progression of long-term complications in insulindependent diabetes mellitus. The Diabetes Control and Complications Trial Research Group. N Engl J Med. 1993;329(14):977-986.

5. Holman RR, Paul SK, Bethel MA, Matthews DR, Neil HA. 10-year follow-up of intensive glucose control in type 2 diabetes. NEngl J Med. 2008;359(15):1577-1589.

6. IDF Diabetes Atlas Update 2012 [webpage on the Internet]. Brussels: International Diabetes Federation; 2012. Available from: http://www. idf.org/diabetesatlas/5e/Update2012. Accessed August 27, 2013.

7. Inzucchi SE. Oral antihyperglycemic therapy for type 2 diabetes: scientific review. JAMA. 2002;287(3):360-372.

8. Fox KM, Gerber Pharmd RA, Bolinder B, Chen J, Kumar S. Prevalence of inadequate glycemic control among patients with type 2 diabetes in the United Kingdom general practice research database: a series of retrospective analyses of data from 1998 through 2002. Clin Ther. 2006;28(3):388-395.

9. Barnett AH. Redefining the role of thiazolidinediones in the management of type 2 diabetes. Vasc Health Risk Manag. 2009;5(1):141-151.

10. Inzucchi SE, Bergenstal RM, Buse JB, et al; American Diabetes Association (ADA); European Association for the Study of Diabetes (EASD). Management of hyperglycemia in type 2 diabetes: a patientcentered approach: position statement of the American Diabetes Association (ADA) and the European Association for the Study of Diabetes (EASD). Diabetes Care. 2012;35(6):1364-1379.

11. Rodbard HW, Jellinger PS, Davidson JA, et al. Statement by an American Association of Clinical Endocrinologists/American College of Endocrinology consensus panel on type 2 diabetes mellitus: an algorithm for glycemic control. Endocr Pract. 2009;15(6): 540-559.

12. Blackburn DF, Swidrovich J, Lemstra M. Non-adherence in type 2 diabetes: practical considerations for interpreting the literature. Patient Prefer Adherence. 2013;7:183-189.

13. Cramer JA. A systematic review of adherence with medications for diabetes. Diabetes Care. 2004;27(5):1218-1224.

14. Asche C, LaFleur J, Conner C. A review of diabetes treatment adherence and the association with clinical and economic outcomes. Clin Ther. 2011;33(1):74-109.

15. Koliaki C, Doupis J. Linagliptin/metformin fixed-dose combination treatment: a dual attack to type 2 diabetes pathophysiology. Adv Ther. 2012;29(12):993-1004.

16. Oral Diabetes Medications Summary Chart [webpage on the Internet]. Boston, MA: Joslin Diabetes Center; 2013. Available from: http:// www.joslin.org/info/oral_diabetes_medications_summary_chart.html. Accessed August 27, 2013.

17. Brazg R, Xu L, Dalla Man C, Cobelli C, Thomas K, Stein PP. Effect of adding sitagliptin, a dipeptidyl peptidase-4 inhibitor, to metformin on 24-h glycaemic control and beta-cell function in patients with type 2 diabetes. Diabetes Obes Metab. 2007;9(2):186-193.

18. Bosi E, Dotta F, Jia Y, Goodman M. Vildagliptin plus metformin combination therapy provides superior glycaemic control to individual monotherapy in treatment-naive patients with type 2 diabetes mellitus. Diabetes Obes Metab. 2009;11(5):506-515.

19. Patlak M. New weapons to combat an ancient disease: treating diabetes. FASEB J. 2002;16(14):1853.
20. Proks P, Reimann F, Green N, Gribble F, Ashcroft F. Sulfonylurea stimulation of insulin secretion. Diabetes. 2002;51 Suppl 3: S368-S376.

21. Cruzan SM. FDA approves new diabetes drug [press release]. 1994 [December 30]. Available from: http://web.archive.org/ web/20070929152824/http://www.fda.gov/bbs/topics/ANSWERS/ ANS00627.html. Accessed July 26, 2013.

22. Nathan DM, Buse JB, Davidson MB, et al. Management of hyperglycemia in type 2 diabetes: a consensus algorithm for the initiation and adjustment of therapy: a consensus statement from the American Diabetes Association and the European Association for the Study of Diabetes. Diabetes Care. 2006;29(8):1963-1972.

23. Van de Laar FA, Lucassen PL, Akkermans RP, Van de Lisdonk EH, Rutten GE, Van Weel C. Alpha-glucosidase inhibitors for type 2 diabetes mellitus. Cochrane Database Syst Rev. 2005;(2):CD003639.

24. Lamanna C, Monami M, Marchionni N, Mannucci E. Effect of metformin on cardiovascular events and mortality: a meta-analysis of randomized clinical trials. Diabetes Obes Metab. 2011;13(3):221-228.

25. Idris I, Warren G, Donnelly R. Association between thiazolidinedione treatment and risk of macular edema among patients with type 2 diabetes. Arch Intern Med. 2012;172(13):1005-1011.

26. Nissen SE, Wolski K. Rosiglitazone revisited: an updated metaanalysis of risk for myocardial infarction and cardiovascular mortality. Arch Intern Med. 2010;170(14):1191-1201.

27. Lewis JD, Ferrara A, Peng T, et al. Risk of bladder cancer among diabetic patients treated with pioglitazone: interim report of a longitudinal cohort study. Diabetes Care. 2011;34(4):916-922.

28. Symlin [webpage on the Internet]. Drugs.com; 2013 [revised December 3, 2010]. Available from: http://www.drugs.com/symlin.html. Accessed August 27, 2013.

29. Kleppinger EL, Vivian EM. Pramlintide for the treatment of diabetes mellitus. Ann Pharmacother. 2003;37(7-8):1082-1089.

30. Hollander PA, Levy P, Fineman MS, et al. Pramlintide as an adjunct to insulin therapy improves long-term glycemic and weight control in patients with type 2 diabetes: a 1-year randomized controlled trial. Diabetes Care. 2003;26(3):784-790.

31. Jones MC. Therapies for diabetes: pramlintide and exenatide. Am Fam Physician. 2007;75(12):1831-1835.

32. Ferrannini E, Ramos SJ, Salsali A, Tang W, List JF. Dapagliflozin monotherapy in type 2 diabetic patients with inadequate glycemic control by diet and exercise: a randomized, double-blind, placebo-controlled, phase 3 trial. Diabetes Care. 2010;33(10):2217-2224.

33. Abrahamson MJ, Peters A. Intensification of insulin therapy in patients with type 2 diabetes mellitus: an algorithm for basal-bolus therapy. Ann Med. 2012;44(8):836-846.

34. Campbell RK. Recommendations for improving adherence to type 2 diabetes mellitus therapy - focus on optimizing insulin-based therapy. Am J Manag Care. 2012;18(Suppl 3):S55-S61.

35. Jonassen I, Havelund S, Hoeg-Jensen T, Steensgaard DB, Wahlund PO, Ribel U. Design of the novel protraction mechanism of insulin degludec, an ultra-long-acting basal insulin. Pharm Res. 2012;29(8): 2104-2114.

36. Bergenstal RM, Rosenstock J, Arakaki RF, et al. A randomized, controlled study of once-daily LY2605541, a novel long-acting basal insulin, versus insulin glargine in basal insulin-treated patients with type 2 diabetes. Diabetes Care. 2012;35(11):2140-2147.

37. Pories WJ, Swanson MS, MacDonald KG, et al. Who would have thought it? An operation proves to be the most effective therapy for adult-onset diabetes mellitus. Ann Surg. 1995;222(3):339-350; discussion 350-332.

38. Buchwald H, Estok R, Fahrbach K, et al. Weight and type 2 diabetes after bariatric surgery: systematic review and meta-analysis. Am J Med. 2009;122(3):248-256. e245.

39. Cao Y, Li Y, Kim J, et al. Orally efficacious novel small molecule 6-chloro-6-deoxy-1,2,3,4-tetra-O-galloyl-alpha-D-glucopyranose selectively and potently stimulates insulin receptor and alleviates diabetes. J Mol Endocrinol. 2013;51(1):15-26. 
40. Ganugapati J, Baldwa A, Lalani S. Molecular docking studies of banana flower flavonoids as insulin receptor tyrosine kinase activators as a cure for diabetes mellitus. Bioinformation. 2012;8(5):216-220.

41. Elrick H, Stimmler L, Hlad CJ Jr, Arai Y. Plasma insulin response to oral and intravenous glucose administration. J Clin Endocrinol Metab. 1964;24:1076-1082.

42. Nauck MA, Homberger E, Siegel EG, et al. Incretin effects of increasing glucose loads in man calculated from venous insulin and C-peptide responses. J Clin Endocrinol Metab. 1986;63(2):492-498.

43. Kumar A. Second line therapy: type 2 diabetic subjects failing on metformin GLP-1/DPP-IV inhibitors versus sulphonylurea/insulin: for GLP-1/DPP-IV inhibitors. Diabetes Metab Res Rev. 2012;28 (Supp1 2): 21-25.

44. Peters A. Incretin-based therapies: review of current clinical trial data. Am J Med. 2010;123(Suppl 3):S28-S37.

45. Drucker DJ, Nauck MA. The incretin system: glucagon-like peptide-1 receptor agonists and dipeptidyl peptidase- 4 inhibitors in type 2 diabetes. Lancet. 11 2006;368(9548):1696-1705.

46. Mentis N, Vardarli I, Köthe LD, et al. GIP does not potentiate the antidiabetic effects of GLP-1 in hyperglycemic patients with type 2 diabetes. Diabetes. 2011;60(4):1270-1276.

47. Wysham CH, Blevins TC, Arakaki R et al. Efficacy and safety of dulaglutide vs placebo and exenatide in type 2 diabetes (AWARD-1). Efficacy and safety of dulaglutide vs placebo and exenatide in type 2 diabetes (AWARD-1). Abstract 66-OR. Presented at: American Diabetes Association (ADA) 73rd Scientific Sessions; June 21-25, 2013; Chicago, IL.

48. Europe approval status for Albiglutide: [webpage on the Internet]. Available from http://www.gsk.com/media/press-releases/2013/regulatoryupdate--gsk-announces-regulatory-submission-for-albig.html. Accessed December 17, 2013.

49. US approval status for Albiglutide : [webpage on the Internet]. Available from http:/google2.fda.gov/searchq=Albiglutide\&client= FDAgov\&site=FDAgov\&lr $=\&$ proxystylesheet $=$ FDAgov\&output $=$ xml_no_dtd\&getfields=*. Accessed December 17, 2013.

50. Lovshin JA, Drucker DJ. Incretin-based therapies for type 2 diabetes mellitus. Nat Rev Endocrinol. 2009;5(5):262-269.

51. Martin JH, Deacon CF, Gorrell MD, Prins JB. Incretin-based therapies - review of the physiology, pharmacology and emerging clinical experience. Intern Med J. 2011;41(4):299-307.

52. Victoza (liraglutide [rDNA origin]) injection: Rems - risk of thy roid C-cell tumors, acute pancreatitis [wepage on the Internet] Silver Spring, MD: US Food and Drug Administration; 2011 [updated June 13, 2011]. Available from: http://www.fda.gov/Safety/ MedWatch/SafetyInformation/SafetyAlertsforHumanMedicalProducts/ ucm258826.htm. Accessed August 27, 2013.

53. Phenomix. Safety and Efficacy study of dutogliptin/PHX1149T to treat type 2 diabetes mellitus. Availabe from http://clinicaltrials.gov/ct2/show/ NCT00690638?term=Dutogliptin\&rank=9. Identifier NCT00690638.

54. Nathan DM, Buse JB, Davidson MB, et al; American Diabetes Association; European Association for Study of Diabetes. Medical management of hyperglycemia in type 2 diabetes: a consensus algorithm for the initiation and adjustment of therapy: a consensus statement of the American Diabetes Association and the European Association for the Study of Diabetes. Diabetes Care. 2009;32(1):193-203.

55. Mazzola N. Review of current and emerging therapies in type 2 diabetes mellitus. Am J Manag Care. 2012;18(Suppl 1):S17-S26.

56. Onglyza ${ }^{\mathrm{TM}}$ (Saxagliptin), a New Treatment for Type 2 Diabetes Mellitus in Adults, Now Available in US Pharmacies [press release]. Bristol-Myers Squibb Company; AstraZeneca; 2009 [August 14] Available from: http://www.bms.com/Documents/news/onglyza_ available.pdf. Accessed July 29, 2013.

57. CHMP Assessment Report for Onglyza. London: European Medicines Agency; 2009. Available from: http://www.ema.europa.eu/docs/en_GB/ document_library/EPAR_-_Public_assessment_report/human/001039/ WC500044319.pdf. Accessed July 29, 2013.
58. Onglyza FAQs [webpage on the Internet]. Bristol-Myers Squibb Company; AstraZeneca Pharmaceuticals LP; 2013. Available from: http://www.onglyza.com/about/faq.aspx. Accessed July 29, 2013.

59. Onglyza (saxagliptin) tablets [prescribing information]. Princeton, NJ: Bristol-Myers Squibb Company; Wilmington, DE: AstraZeneca Pharmaceuticals LP; 2013. Available from: http://packageinserts.bms. com/pi/pi_onglyza.pdf. Accessed July 29, 2013.

60. 74 studies found for: saxagliptin [webpage on the Internet]. ClinicalTrials.gov; 2013. Available from: http://clinicaltrials.gov/ct2/ results?term=saxagliptin\&Search=Search. Accessed July 29, 2013.

61. Dickersin K, Scherer R, Lefebvre C. Identifying relevant studies for systematic reviews. BMJ. 1994;309(6964):1286-1291.

62. Ho PM, Rumsfeld JS, Masoudi FA, et al. Effect of medication nonadherence on hospitalization and mortality among patients with diabetes mellitus. Arch Intern Med. 2006;166(17):1836-1841.

63. Adherence to long-term therapies: evidence for action [webpage on the Internet]. Geneva: World Health Organization; 2013; Available from: http://www.who.int/chp/knowledge/publications/adherence_report/en/. Accessed July 27, 2013.

64. Melikian C, White TJ, Vanderplas A, Dezii CM, Chang E. Adherence to oral antidiabetic therapy in a managed care organization: a comparison of monotherapy, combination therapy, and fixed-dose combination therapy. Clin Ther. 2002;24(3):460-467.

65. Hermans MP, Delibasi T, Farmer I, et al. Effects of saxagliptin added to sub-maximal doses of metformin compared with uptitration of metformin in type 2 diabetes: the PROMPT study. Curr Med Res Opin. 2012;28(10):1635-1645

66. Upreti VV, Keung CF, Boulton DW, et al. Bioequivalence of saxagliptin/ metformin immediate release (IR) fixed-dose combination tablets and single-component saxagliptin and metformin IR tablets in healthy adult subjects. Clin Drug Investig. 2013;33(5):365-374.

67. Boulton DW, Smith CH, Li L, Huang J, Tang A, LaCreta FP. Bioequivalence of saxagliptin/metformin extended-release (XR) fixed-dose combination tablets and single-component saxagliptin and metformin XR tablets in healthy adult subjects. Clin Drug Investig. 2011;31(9):619-630.

68. DeFronzo RA, Hissa MN, Garber AJ, et al; Saxagliptin 014 Study Group. The efficacy and safety of saxagliptin when added to metformin therapy in patients with inadequately controlled type 2 diabetes with metformin alone. Diabetes Care. 2009;32(9):1649-1655.

69. Liu Y, Hong T. Combination therapy of dipeptidyl peptidase-4 inhibitors and metformin in type 2 diabetes: rationale and evidence. Diabetes Obes Metab. Epub May 13, 2013.

70. Chacra AR, Tan GH, Ravichandran S, List J, Chen R; CV181040 Investigators. Safety and efficacy of saxagliptin in combination with submaximal sulphonylurea versus up-titrated sulphonylurea over 76 weeks. Diab Vasc Dis Res. 2011;8(2):150-159.

71. Fass AD, Gershman JA. Efficacy and safety of dipeptidyl peptidase-4 inhibitors in combination with metformin. Adv Ther. 2013;30(4): 337-353.

72. Cook W, Bryzinski B, Slater J, Frederich R, Allen E. Saxagliptin efficacy and safety in patients with type 2 diabetes mellitus and cardiovascular disease history or cardiovascular risk factors: results of a pooled analysis of phase 3 clinical trials. Postgrad Med. 2013;125(3):145-154.

73. Gerstein HC, Miller ME, Byington RP, et al. Effects of intensive glucose lowering in type 2 diabetes. N Engl J Med. 2008;358(24):2545-2559.

74. Scirica BM, Bhatt DL, Braunwald E, et al. The design and rationale of the saxagliptin assessment of vascular outcomes recorded in patients with diabetes mellitus-thrombolysis in myocardial infarction (SAVORTIMI) 53 study. Am Heart J. 2011;162(5):818-825. e6.

75. AstraZeneca and Bristol-Myers Squibb announce top line results for SAVOR-TIMI-53 cardiovascular outcomes trial of Onglyza ${ }^{\circledR}$ (saxagliptin) [press release]. Princeton, NJ: Bristol-Myers Squibb; Wilmington, DE: AstraZeneca; 2013 [June 19]. Available from: http://news.bms.com/ press-release/astrazeneca-and-bristol-myers-squibb-announce-top-lineresults-savor-timi-53-cardiovas. Accessed July 29, 2013. 
76. Karyekar CS, Ravichandran S, Allen E, Fleming D, Frederich R. Tolerability and efficacy of glycemic control with saxagliptin in older patients (aged $\geq 65$ years) with inadequately controlled type 2 diabetes mellitus. Clin Interv Aging. 2013;8:419-430.

77. Jerums G, Panagiotopoulos S, Premaratne E, MacIsaac RJ. Integrating albuminuria and GFR in the assessment of diabetic nephropathy. Nat Rev Nephrol. 2009;5(7):397-406.

78. Lipska KJ, Bailey CJ, Inzucchi SE. Use of metformin in the setting of mild-to-moderate renal insufficiency. Diabetes Care. 2011;34(6): 1431-1437.

79. Zanchi A, Lehmann R, Philippe J. Antidiabetic drugs and kidney disease - recommendations of the Swiss Society for Endocrinology and Diabetology. Swiss Med Wkly. 2012;142:w13629.

80. Nowicki M, Rychlik I, Haller H, et al. Long-term treatment with the dipeptidyl peptidase-4 inhibitor saxagliptin in patients with type 2 diabetes mellitus and renal impairment: a randomised controlled 52-week efficacy and safety study. Int J Clin Pract. 2011;65(12):1230-1239.

81. Cornell SA. A patient-centred approach to treatment with incretin-based agents in patients with type 2 diabetes. J Clin Pharm Ther. 2013;38(3): 181-189.

82. Peyrot M, Rubin RR, Lauritzen T, Snoek FJ, Matthews DR, Skovlund SE. Psychosocial problems and barriers to improved diabetes management: results of the Cross-National Diabetes Attitudes, Wishes and Needs (DAWN) Study. Diabet Med. 2005;22(10):1379-1385.

83. Cornell S. Differentiating among incretin therapies: a multiple-target approach to type 2 diabetes. J Clin Pharm Ther. 2012;37(5):510-524.

84. Nau DP. Recommendations for improving adherence to type 2 diabetes mellitus therapy - focus on optimizing oral and non-insulin therapies. Am J Manag Care. 2012;18(Supp1 3):S49-S54.

85. Goke B, Gallwitz B, Eriksson J, Hellqvist A, Gause-Nilsson I. Saxagliptin is non-inferior to glipizide in patients with type 2 diabetes mellitus inadequately controlled on metformin alone: a 52-week randomised controlled trial. Int J Clin Pract. 2010;64(12):1619-1631.

86. Nadeau DA. Partnering with patients to improve therapeutic outcomes: incretin-based therapy for type 2 diabetes. Postgrad Med. 2010;122(3): $7-15$.

87. Jendle J, Torffvit O, Ridderstrale M, Lammert M, Ericsson A, Bogelund M. Willingness to pay for health improvements associated with anti-diabetes treatments for people with type 2 diabetes. Curr Med Res Opin. 2010;26(4):917-923.
88. Erhardt W, Bergenheim K, Duprat-Lomon I, McEwan P. Cost effectiveness of saxagliptin and metformin versus sulfonylurea and metformin in the treatment of type 2 diabetes mellitus in Germany: a Cardiff diabetes model analysis. Clin Drug Investig. 2012;32(3): 189-202.

89. Hansen RA, Farley JF, Droege M, Maciejewski ML. A retrospective cohort study of economic outcomes and adherence to monotherapy with metformin, pioglitazone, or a sulfonylurea among patients with type 2 diabetes mellitus in the United States from 2003 to 2005. Clin Ther. 2010;32(7):1308-1319.

90. Elgart JF, Caporale JE, Gonzalez L, Aiello E, Waschbusch M, Gagliardino JJ. Treatment of type 2 diabetes with saxagliptin: a pharmacoeconomic evaluation in Argentina. Health Econ Rev. 2013;3(1):11

91. Nita ME, Eliaschewitz FG, Ribeiro E, et al. Cost-effectiveness and budget impact of saxagliptine as additional therapy to metformin for the treatment of diabetes mellitus type 2 in the Brazilian private health system. Rev Assoc Med Bras. 2012;58(3):294-301.

92. Aphorisms [webpage on the Internet]. Available from: http://classics. mit.edu/Hippocrates/aphorisms.1.i.html. Accessed July 27, 2013.

93. Montori VM, Gafni A, Charles C. A shared treatment decision-making approach between patients with chronic conditions and their clinicians: the case of diabetes. Health Expect. 2006;9(1):25-36.

94. Porzsolt F, Clouth J, Deutschmann M, Hippler HJ. Preferences of diabetes patients and physicians: a feasibility study to identify the key indicators for appraisal of health care values. Health Qual Life Outcomes. 2010;8:125.

95. Drugs.com [homepage on the Internet]. Drugs.com; 2013. Available from: http://www.drugs.com. Accessed July 21, 2013.

96. Frederich R, McNeill R, Berglind N, Fleming D, Chen R. The efficacy and safety of the dipeptidyl peptidase-4 inhibitor saxagliptin in treatment- naïve patients with type 2 diabetes mellitus: a randomized controlled trial. Diabetol Metab Syndr. 2012;4(1):36.

97. Dave DJ. Saxagliptin: a dipeptidyl peptidase-4 inhibitor in the treatment of type 2 diabetes mellitus. J Pharmacol Pharmacother. 2011;2(4): $230-235$.
Patient Preference and Adherence

\section{Publish your work in this journal}

Patient Preference and Adherence is an international, peer-reviewed, open access journal focusing on the growing importance of patient preference and adherence throughout the therapeutic continuum. Patient satisfaction, acceptability, quality of life, compliance, persistence and their role in developing new therapeutic modalities and compounds to

\section{Dovepress}

optimize clinical outcomes for existing disease states are major areas of interest. This journal has been accepted for indexing on PubMed Central. The manuscript management system is completely online and includes a very quick and fair peer-review system. Visit http://www.dovepress.com/ testimonials.php to read real quotes from published authors. 